\title{
Emergency Department Management of Suspected Carbon Monoxide Poisoning: Role of Pulse CO-Oximetry
}

\author{
Mustapha Sebbane MD PhD, Pierre-Géraud Claret MD, \\ Grégoire Mercier MD PhD, Sophie Lefebvre PhD, Richard Théry MD, \\ Richard Dumont MD, Michel Maillé MD, Jean-Paul Richard MD, \\ Jean-Jacques Eledjam MD PhD, and Jean-Emmanuel de La Coussaye MD PhD
}

\begin{abstract}
BACKGROUND: The RAD-57 pulse CO-oximeter is a lightweight device allowing noninvasive measurement of blood carboxyhemoglobin $\left(\mathrm{S}_{\mathrm{pCO}}\right)$. We assessed the diagnostic value of pulse $\mathrm{CO}$ oximetry, comparing $S_{p C O}$ values from the RAD-57 to standard laboratory blood carboxyhemoglobin $(\mathrm{COHb})$ measurement in emergency department patients with suspected carbon monoxide (CO) poisoning. METHODS: This was a prospective, diagnostic accuracy study according to the Standards for the Reporting of Diagnostic Accuracy Studies criteria in consecutive adult emergency department patients with suspected $\mathrm{CO}$ poisoning. $\mathrm{S}_{\mathrm{pCO}}$ was measured with the RAD-57 simultaneously with blood sampling for laboratory blood gas analysis. We made no changes to our standard management of $\mathrm{CO}$ poisoning. Blood $\mathrm{COHb}>5 \%$ for non-smokers, and $>10 \%$ for smokers were applied as the reference standard. RESULTS: We included 93 subjects: 37 smokers and 56 non-smokers. CO poisoning was diagnosed in 26 subjects $(28 \%)$. The $\mathrm{S}_{\mathrm{pCO}}$ values ranged from $1 \%$ to $30 \%$, with a median of $4 \%$ (IQR 2.7-7.3\%). The COHb values ranged from $0 \%$ to $34 \%$, with a median of $5 \%$ (IQR 2-9\%). The mean differences between the $\mathrm{COHb}$ and $\mathrm{S}_{\mathrm{pco}}$ values were $-0.2 \% \pm 3.3 \%(95 \%$ limits of agreement of $-6.7 \%$ and $6.3 \%$ ) for the whole cohort, $-\mathbf{0 . 7 \%}$ (limits of agreement $-7.7 \%$ and $6.2 \%$ ) for the non-smokers, and $0.6 \%$ (limits of agreement $-\mathbf{5 . 0 \%}$ and 6.2\%) for the smokers. The optimal thresholds for detecting $\mathrm{CO}$ poisoning were $\mathrm{S}_{\mathrm{pCO}}$ of $9 \%$ and $6 \%$ for smokers and non-smokers, respectively. CONCLUSIONS: $S_{\mathrm{pco}}$ measured with the RAD-57 was not a substitute for standard blood $\mathrm{COHb}$ measurement. However, noninvasive pulse CO-oximetry could be useful as a first-line screening test, enabling rapid detection and management of COpoisoned patients in the emergency department. Key words: carbon monoxide; $\mathrm{CO}$ poisoning; $\mathrm{CO}$ oximetry; pulse oximetry; emergency department; sensitivity; specificity. [Respir Care 2013;58(10):16141620. () 2013 Daedalus Enterprises]
\end{abstract}

\section{Introduction}

Carbon monoxide $(\mathrm{CO})$ poisoning is the main cause of death by poisoning in Europe and the United States. ${ }^{1,2}$ In

The authors are affiliated with Département des Urgences, Centre Hospitalier Régional Universitaire Lapeyronie, Montpellier, France, with the exception of Dr Mercier, who is affiliated with the Département d'Information Médicale at that institution, and Drs Claret and de La Coussaye, who are affiliated with Département des Urgences, Hôpital Universitaire Carémeau, Nimes, France.

Dr Sebbane presented a version of this paper at the fourth annual conference of the French Society for Emergency Medicine, held June 2-4, 2010, in Paris, France, and at the French Society for Anesthesia and Intensive Care, held September 22-25, 2010, in Paris, France.
France approximately 6,000 patients are treated annually for suspected or confirmed $\mathrm{CO}$ exposure, of whom 2,500 are admitted to hospital and 300 die. ${ }^{3}$ Due to potential severity and the necessity of immediate therapy, there is an urgent need for rapid, reliable screening and management

\footnotetext{
The authors have disclosed no conflicts of interest.

Correspondence: Mustapha Sebbane MD PhD, Département des Urgences, Centre Hospitalier Régional Universitaire Lapeyronie, 371 Avenue du Doyen Gaston Giraud, 34295 -Montpellier, Cedex 5, France. E-mail: m-sebbane@chu-montpellier.fr.
}

DOI: $10.4187 /$ respcare.02313 
of $\mathrm{CO}$ poisoning. ${ }^{4,5}$ However, the clinical signs are polymorphic, nonspecific, and vary in time and from one patient to another. 6,7 The diagnosis of $\mathrm{CO}$ poisoning remains a challenge, especially in the context of occult $\mathrm{CO}$ poisoning, in the absence of specific symptoms, or in an evocative context (fire, failing heating systems, unhealthy housing environment, presence of other victims, including animals).

Besides the clinical signs and circumstances, the diagnosis of $\mathrm{CO}$ poisoning relies on measurement of blood carboxyhemoglobin $(\mathrm{COHb})$ via venous or arterial blood gas analysis. ${ }^{8}$ A lightweight pulse $\mathrm{CO}$-oximeter enabling noninvasive $\mathrm{CO}$ measurement $\left(\mathrm{S}_{\mathrm{pCO}}\right)$ through a fingertip sensor has been approved for use in clinical practice since 2005 (RAD-57, Masimo, Irvine, California). However, clinical data supporting the use of noninvasive pulse COoximetry in patients with suspected $\mathrm{CO}$ poisoning in the actual clinical context is still sparse. Most of the published studies have evaluated population-based screening or small populations of patients with suspected $\mathrm{CO}$ poisoning, with relatively low levels or range of $\mathrm{CO}$ exposure, and the results from accurate comparisons between RAD-57 measurements and laboratory blood gas analysis in emergency department (ED) patients with suspected $\mathrm{CO}$ poisoning are debated. ${ }^{9}$

The first preliminary study of the RAD-57 in ED patients with $\mathrm{CO}$ poisoning showed good agreement between the RAD-57 and laboratory blood gas analysis. ${ }^{10}$ This was further confirmed in $64 \mathrm{ED}$ patients included regardless of the cause of ED admission. ${ }^{11}$ An acceptable difference between RAD-57 and laboratory analysis has also been reported in other clinical settings, including a hyperbaric center and a burn unit, in studies with small numbers of poisoned patients with high $\mathrm{COHb}$ levels. ${ }^{12,13}$

However, 3 recent and better powered ED studies found either poor or acceptable concordance between RAD-57 and laboratory analysis. The reliability of the RAD-57 in detecting $\mathrm{CO}$ poisoning was advocated in one study. ${ }^{14-16}$ Acceptable agreement and reliability of the RAD-57 have been reported in laboratory studies with human volunteers. ${ }^{17,18}$ This raises the need for more clinical testing of the RAD-57 in real ED conditions.

Rapid and noninvasive detection of elevated $\mathrm{COHb}$ could improve diagnosis and management of $\mathrm{CO}$ poisoning in emergency medicine, so we evaluated the reliability and accuracy of the RAD-57 as a screening tool for acute CO poisoning in $\mathrm{ED}$ patients with suspected $\mathrm{CO}$ poisoning.

\section{Methods}

This study was approved by our local ethics committee, which waived the requirement for written informed consent.

\section{QUICK LOOK}

\section{Current knowledge}

Carbon monoxide $(\mathrm{CO})$ poisoning is the main cause of poisoning death in the western world. The potential severity and need for immediate treatment require a rapid and reliable screening technique for $\mathrm{CO}$ poisoning, which is currently guided by suspicion based on vague symptoms and knowledge of the potential exposure. The gold standard for diagnosis of $\mathrm{CO}$ poisoning is blood carboxyhemoglobin $(\mathrm{COHb})$ measurement via laboratory CO-oximetry.

\section{What this paper contributes to our knowledge}

Noninvasive measurement of $\mathrm{COHb}$ with the RAD-57 device cannot be used as a substitute for standard blood $\mathrm{COHb}$ measurement in emergency department patients with suspected CO poisoning. However, the RAD-57 may allow rapid detection of CO-poisoned patients, among emergency department patients with suspected $\mathrm{CO}$ poisoning.

\section{Study Design and Setting}

This was a prospective, diagnostic accuracy study according to the Standards for the Reporting of Diagnostic Accuracy Studies. The study was conducted in an urbanbased university hospital ED, with a census of 50,000 visits per year. Consecutive adult patients presenting with suspected $\mathrm{CO}$ poisoning were included over a 19-month period. $\mathrm{S}_{\mathrm{pCO}}$ was measured with the RAD-57, and simultaneously venous blood was sampled for standard laboratory blood gas analysis. We made no changes to our standard $\mathrm{CO}$ poisoning management.

\section{Subjects and Interventions}

Subjects were consecutive patients, $\geq 18$ years old, admitted to the ED for suspected CO exposure. Suspicion of $\mathrm{CO}$ poisoning was evoked according to clinical symptoms or circumstances. After complete physical examination, the subjects underwent venous blood sampling for standard laboratory $\mathrm{COHb}$ measurement, according to our standard ED management procedures for $\mathrm{CO}$ poisoning, and, simultaneously, CO-oximetry with the RAD-57. The following data were prospectively collected: reason for admission, age, sex, physiologic variables, smoking status, heart rate, blood pressure, $\mathrm{S}_{\mathrm{pO}}, \mathrm{S}_{\mathrm{pCO}}$, standard laboratory tests (including blood $\mathrm{COHb}$ ), and electrocardiography. The timing of the blood sampling and RAD-57 measure- 
ments were also recorded. Data were entered into a database (Excel, Microsoft, Redmond, Washington).

\section{Pulse CO-Oximetry}

Pulse CO-oximetry was carried out by nursing staff trained in the use of the RAD-57, with the adult size sensor on the 3rd or 4th digit, according to the manufacturer's recommendations. Nail polish was removed if necessary. $\mathrm{S}_{\mathrm{pCO}}$ is expressed as a percentage of the total hemoglobin.

\section{Standard Blood Gas Analysis}

Venous blood was collected into ethylenediaminetetraacetic acid (EDTA) treated tubes (Beckton Dickinson) and sent to the toxicology laboratory for $\mathrm{COHb}$ testing. Blood $\mathrm{COHb}$ was analyzed by derivative spectrophotometry, using an automated CO-oximeter (IL 682, Instrumentation Laboratory, Milan, Italy), which measured $\mathrm{COHb}$ within a range of $0-100 \%$, with an accuracy of $\pm 0.5 \%$ and is reported as a percentage of the total hemoglobin.

Diagnosis of $\mathrm{CO}$ poisoning was deemed confirmed when the laboratory $\mathrm{COHb}$ value was $>5 \%$ in non-smokers, or $>10 \%$ in smokers. $^{4}$

\section{Primary Data Analysis}

Descriptive statistics were used to describe the variables, including mean \pm SD and median and range. The time interval between the RAD-57 measurement and blood sampling was calculated as an absolute value and is reported in hours and minutes. Correlation between $\mathrm{S}_{\mathrm{pCO}}$ and $\mathrm{COHb}$ was tested using intraclass correlation coefficient, along with 95\% CI based on Fisher transformation. Agreement between the 2 methods was assessed according to Bland-Altman. ${ }^{19}$ Differences between the measurements were calculated as $\mathrm{COHb}$ minus $\mathrm{S}_{\mathrm{pCO}}$. The mean $\pm \mathrm{SD}$ and range values were calculated for the differences between measurements to assess bias and imprecision. Upper and lower limits of agreement were calculated as the mean difference $\pm 1.96 \mathrm{SD}$.

The overall diagnostic value of $S_{\mathrm{pCO}}$ was quantified by calculating the area under the receiver operating characteristic curve, using the trapezoidal method, with 95\% CI. $\mathrm{S}_{\mathrm{pCO}}$ thresholds for the identification of $\mathrm{CO}$ poisoning were calculated using receiver operating characteristic curve analysis, based on normal $\mathrm{COHb}$ cutoffs $(5 \%$ in non-smokers and $10 \%$ in smokers). Optimal thresholds for the best combined sensitivity and specificity were determined using the Youden index. Diagnostic parameters (sensitivity, specificity, and predictive values) were calculated for each $\mathrm{S}_{\mathrm{pCO}}$ threshold, along with $95 \% \mathrm{CI}$, based on normal approximation. The significance level was set at $P \leq .05$ for all tests. Statistical analysis was performed by
Table 1. Subject Characteristics

\begin{tabular}{lc}
\hline \hline Age, mean \pm SD, y & $43 \pm 20$ (range 18-92) \\
Male, no. $(\%)$ & $42(45)$ \\
Female, no. (\%) & $51(55)$ \\
Smoker, no. (\%) & $37(40)$ \\
Non-smoker, no. (\%) & $56(60)$ \\
Type of carbon monoxide exposure, no. (\%) & \\
Domestic source & $37(40)$ \\
Smoke inhalation & $53(57)$ \\
Other & $3(3)$ \\
COHb, median (IQR), $\%$ & \\
Measured from blood sample & \\
$\quad$ All subjects & $4(2.7-7.3)$ \\
Smokers & $5(4.0-7.0)$ \\
Non-smokers & $6(2.0-8.0)$ \\
Measured via CO-oximetry & \\
$\quad$ All subjects & $5(2-9)$ \\
Smokers & $6(3-7)$ \\
Non-smokers & $5(2-10)$ \\
\hline COHb = carboxyhemoglobin & \\
\hline
\end{tabular}

author GM at Département d'information Médicale, Centre Hospitalier Régional Universitaire Lapeyronie, with statistics software (SAS 9, SAS Institute, Cary, North Carolina).

\section{Results}

\section{Subjects}

During the 19-month study, 95 patients with suspected CO poisoning were eligible for inclusion. Two patients were excluded for missing data, and 93 subjects were included (Table 1). A diagnosis of CO-poisoning was retained for 26 subjects (28\%) (21 non-smokers and 5 smokers), based on the widely accepted $5 \%$ and $10 \% \mathrm{COHb}$ thresholds for non-smokers and smokers, respectively. The median $\mathrm{COHb}$ levels were $7.8 \%$ (IQR 6.6-11.8\%) and $12.0 \%$ (IQR $10.8-15.5 \%$ ) in the non-smokers and smokers, respectively.

\section{Agreement Between $\mathrm{COHb}$ and $\mathrm{S}_{\mathrm{pCO}}$}

The RAD-57 measurements and blood sampling were performed within a mean of $19 \mathrm{~min}$ (95\% CI 10-29 min). RAD-57 measurement and blood sampling were performed simultaneously in $33 \%$ of cases. $\mathrm{S}_{\mathrm{pCO}}$ was tested before blood sampling in $46 \%$ of cases. The $\mathrm{S}_{\mathrm{pCO}}$ values ranged from $1 \%$ to $30 \%$, and the $\mathrm{COHb}$ values ranged from $0 \%$ to $34 \%$. The median values are shown in Table 1 .

Moderate correlation was found between the $\mathrm{COHb}$ and $\mathrm{S}_{\mathrm{pCO}}$ values: $\mathrm{r}=0.70(95 \% \mathrm{CI} 0.58-0.79)($ Fig. 1). Agree- 


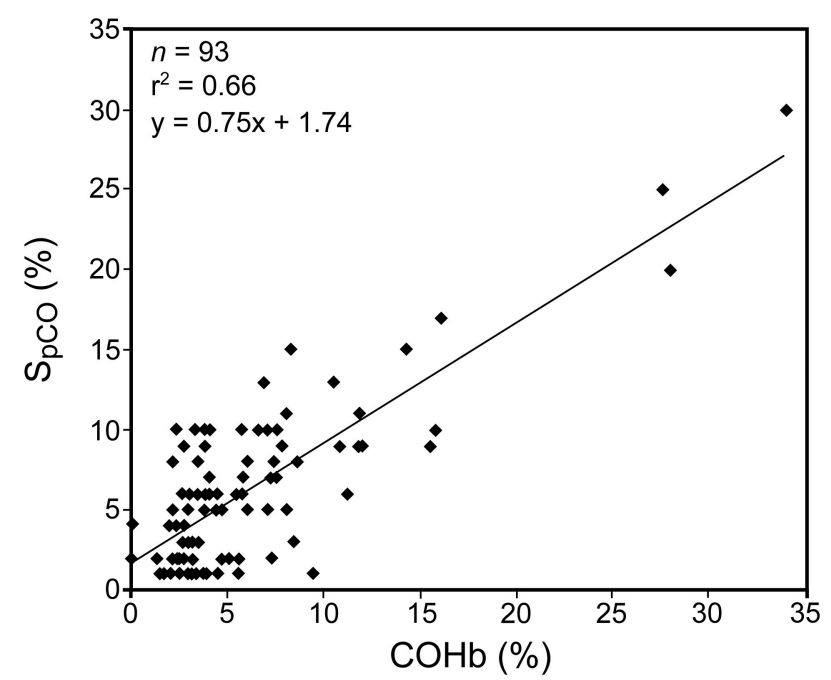

Fig. 1. Carboxyhemoglobin ( $\mathrm{COHb}$ ) measured with the RAD57 pulse $\mathrm{CO}$-oximeter $\left(\mathrm{S}_{\mathrm{pco}}\right)$ versus via laboratory blood gas analysis.

ment between $\mathrm{S}_{\mathrm{pCO}}$ and $\mathrm{COHb}$ was assessed with the Bland-Altman method. The mean $\pm \mathrm{SD}$ bias $(\mathrm{COHb}$ minus $\left.\mathrm{S}_{\mathrm{pCO}}\right)$ and precision were $-0.2 \pm 3.3 \%(95 \% \mathrm{CI}$ -0.44 to $0.02 \%$, limits of agreement $-6.7 \%$ and $6.3 \%$ ) for the entire cohort (Fig. 2). For the non-smokers the mean bias and precision were $-0.7 \pm 3.6 \%(95 \% \mathrm{CI}-1.04$ to -0.41 , limits of agreement $-7.7 \%$ and $6.2 \%$, see Fig. 2). For the smokers the mean bias and precision were $0.6 \pm 2.8 \%(95 \% \mathrm{CI}-0.34$ to 1.48 , limits of agreement $-5.0 \%$ and $6.2 \%$, see Fig. 2).

\section{Diagnostic Performance of $\mathrm{S}_{\mathrm{pCO}}$}

Receiver operating characteristic curves were used to identify $\mathrm{S}_{\mathrm{pCO}}$ thresholds to discriminate between poisoned and non-poisoned subjects, with the best combined sensitivity and specificity. The area under the receiver operating characteristic curve was 0.84 (95\% CI 0.74-0.94) for the entire cohort. An $\mathrm{S}_{\mathrm{pCO}}$ of $9 \%$ provided the optimal threshold for detecting subjects with $\mathrm{COHb}>10 \%$ in the entire cohort. The area under the curve of $\mathrm{S}_{\mathrm{pCO}}$ was 0.83 (95\% CI 0.71-0.95) for non-smokers, and 0.98 (95\% CI 0.89-1) for smokers.

The optimal $\mathrm{S}_{\mathrm{pCO}}$ threshold was $6 \%$ for non-smokers, and $9 \%$ for smokers (Fig. 3). The performance characteristics for each $\mathrm{S}_{\mathrm{pCO}}$ threshold are shown in Table 2. Seven false negatives were found.

\section{Discussion}

Our results confirm that the RAD-57's $\mathrm{S}_{\mathrm{pCO}}$ measurements cannot be used as a substitute for standard blood $\mathrm{COHb}$ measurement in $\mathrm{ED}$ subjects with suspected $\mathrm{CO}$ poisoning. However, our results, obtained in real ED con-
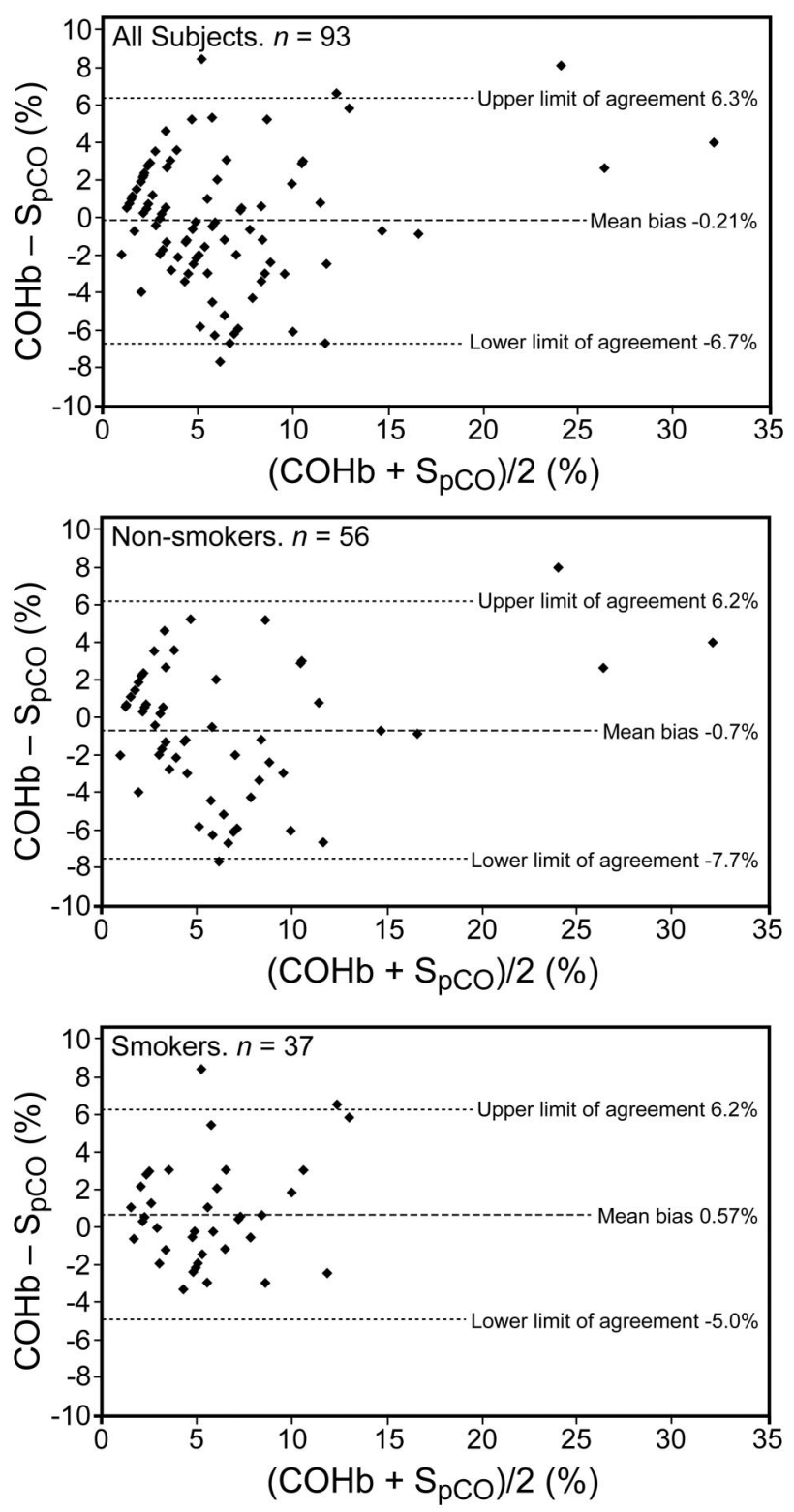

Fig. 2. Bland-Altman plots of the difference between carboxyhemoglobin $(\mathrm{COHb})$ measured with the RAD57 pulse CO-oximeter $\left(\mathrm{S}_{\mathrm{pco}}\right)$ and measured via laboratory blood gas analysis, against the average of measurements.

ditions, also show that noninvasive pulse CO-oximetry allows rapid detection of $\mathrm{CO}$-poisoned subjects, among ED subjects with suspected $\mathrm{CO}$ poisoning.

We found $\mathrm{S}_{\mathrm{pCO}}$, with a bias of $-0.2 \%$, to slightly underestimate the blood $\mathrm{COHb}$ levels in our entire ED subject cohort. However, $\mathrm{S}_{\mathrm{pCO}}$ tended to overestimate $\mathrm{COHb}$ in smokers, with a bias of $0.6 \%$. The precision of the RAD-57 measurements was $3.3 \%$ in our study cohort, which closely matches the measurement precision claimed by the manufacturer (3\%), supporting the reliability of the noninvasive RAD-57 in actual ED conditions. 

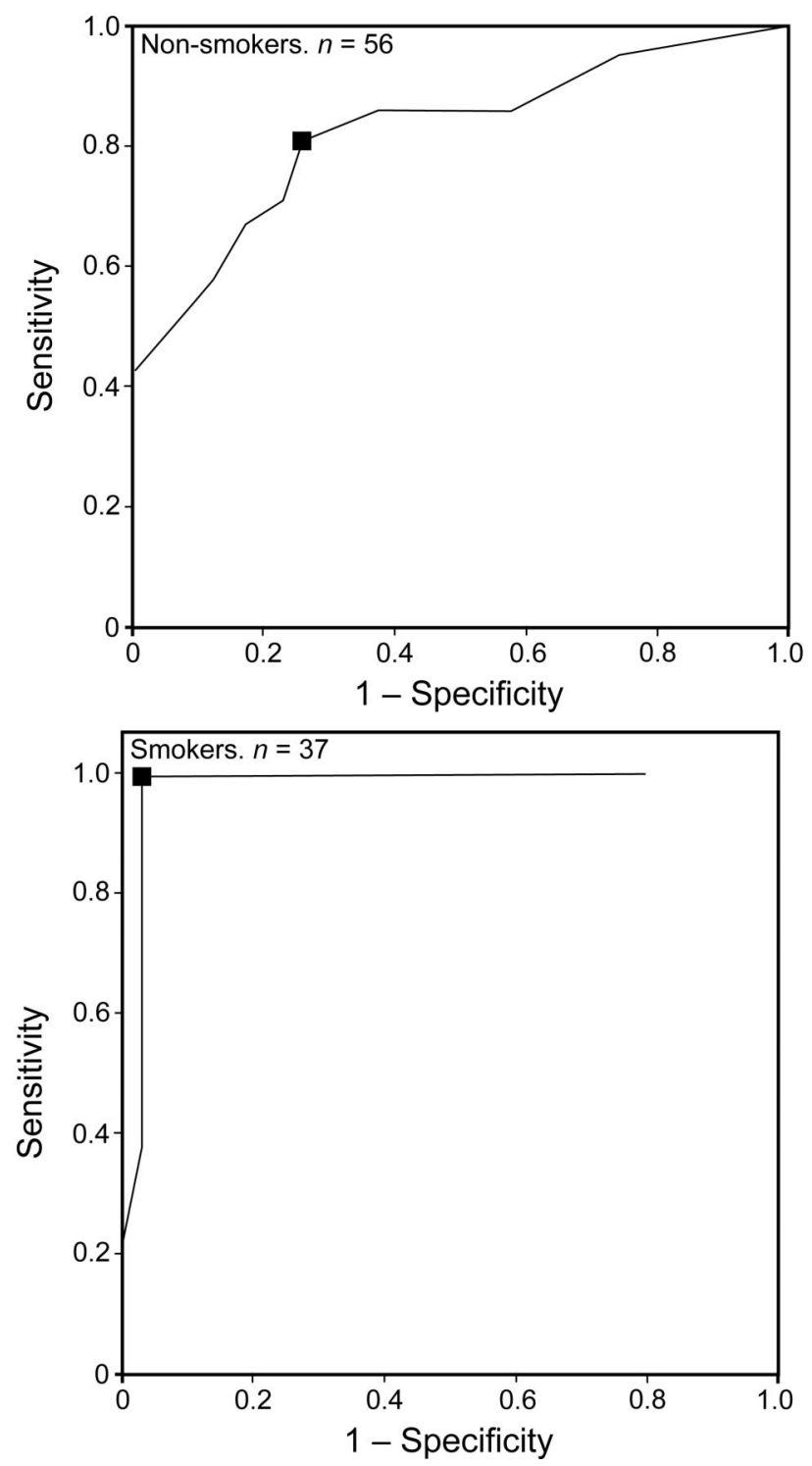

Fig. 3. Receiver operating characteristic curves showing optimum $\mathrm{S}_{\mathrm{pco}}$ cutoffs for screening CO-poisoned subjects. Blood carboxyhemoglobin $(\mathrm{COHb})$ of $>5 \%$ in non-smokers, and $>10 \%$ in smokers, were used as the reference standard for diagnosing $\mathrm{CO}$ poisoning.

The limits of agreement between $\mathrm{S}_{\mathrm{pCO}}$ and $\mathrm{COHb}$ were $-6.7 \%$ to $6.3 \%$, which are similar to most limits of agreement previously reported from EDs, burn centers, hyperbaric centers, and respiratory departments, and in healthy volunteers. ${ }^{10-12,17,18}$ Our Bland-Altman analysis shows that the higher the $\mathrm{COHb}$ value, the more the $\mathrm{S}_{\mathrm{pCO}}$ value tends to overestimate the $\mathrm{COHb}$ value.

We found 6 subjects $(6 \%)$ with $\mathrm{COHb}$ levels higher than $15 \%$ in our ED subject cohort. The accuracy and reliability of $\mathrm{S}_{\mathrm{pCO}}$ for detecting $\mathrm{COHb}>15 \%$ have been explored in a physiological study that included 10 healthy volunteers under experimental conditions. A good corre- lation was found: limits of agreement $-5.5 \%$ to $3.1 \%$, bias $1.2 \%$, and accuracy $\pm 2.2 \%$, which is close to what we found in ED subjects with suspected $\mathrm{CO}$ poisoning, further supporting our findings. ${ }^{17}$

Multiple factors may influence the discrepancy between $\mathrm{S}_{\mathrm{pCO}}$ and $\mathrm{COHb}$ measurements. Besides the $\mathrm{S}_{\mathrm{pCO}}$ value, smoking, age, and time interval between measurements have been identified as independent influencing factors. ${ }^{15}$ Methemoglobin, body temperature, and blood pressure may also influence $\mathrm{S}_{\mathrm{pCO}}$ accuracy. ${ }^{16}$ Additionally, factors related to the use of the RAD-57 device may alter $\mathrm{S}_{\mathrm{pCO}}$ measurements, including an incorrectly positioned fingertip sensor, or the presence of false nails, or nail polish or dye such as henna on the nails and fingertips. Nonetheless, our study shows that pulse CO-oximetry may be an effective tool in detecting CO-poisoning in subjects with suspected $\mathrm{CO}$ poisoning, in real ED conditions, and with an acceptable level of accuracy.

Using commonly accepted blood $\mathrm{COHb}$ thresholds for the diagnosis of CO poisoning ( $>10 \%$ in smokers or $5 \%$ in non-smokers), our study identified $2 \mathrm{~S}_{\mathrm{pCO}}$ thresholds that can be used to distinguish $\mathrm{CO}$ poisoned subjects from non-poisoned ones, with good sensitivity, specificity, and predictive values, when considering the subject's smoking status: $S_{\mathrm{pCO}}$ threshold $\geq 9 \%$ in smokers, and $\geq 6 \%$ in non-smokers. The optimal $\mathrm{S}_{\mathrm{pCO}}$ threshold derived from our ED cohort (9\%) is slightly higher than that reported by Roth et al. ${ }^{15}$ They reported an $\mathrm{S}_{\mathrm{pCO}}$ upper limit of normal cutoff of $6.6 \%$ in a large screening for occult $\mathrm{CO}$ poisoning in the ED. Their analysis was based on a limited number of subjects with a diagnosis of $\mathrm{CO}$ poisoning, and the normal $\mathrm{COHb}$ cutoff used for confirming the diagnosis of $\mathrm{CO}$ poisoning was not disclosed.

Furthermore, our findings support the possibility of developing an algorithm for sorting and prioritizing subjects with suspected CO poisoning upon arrival at the ED. Risk stratification could then be based on pulse CO-oximetry result and subject smoking status. Subjects with suspected $\mathrm{CO}$ poisoning and first-line, positive RAD-57 testing ( $\mathrm{S}_{\mathrm{pCO}} \geq 9 \%$ in smokers, or $\geq 6 \%$ in non-smokers) could benefit from immediate care. However, a negative RAD-57 test will not exclude standard blood $\mathrm{COHb}$ measurement to confirm $\mathrm{CO}$ poisoning.

A feature of $\mathrm{CO}$ poisoning is its collective nature. Rapid detection and prioritizing of patients with suspected $\mathrm{CO}$ poisoning could prove crucial in the $\mathrm{ED}$, allowing time optimization with a strategy that includes detection, prioritizing, and care. More rapid diagnosis and initiation of hyperbaric oxygen therapy in $\mathrm{CO}$ poisoned patients evaluated by pulse CO-oximetry, compared with laboratory CO-oximetry, have recently been shown in a retrospective study. ${ }^{20}$ Further studies are needed to optimize the diagnostic value of pulse $\mathrm{CO}$-oximetry according to the clinical setting, especially the pre-hospital screening. 
Table 2. Performance of the RAD-57 Pulse CO-Oximeter for Detecting CO Poisoning*

\begin{tabular}{|c|c|c|c|}
\hline & $\begin{array}{c}\text { Non-smokers } \\
n=56\end{array}$ & $\begin{array}{c}\text { Smokers } \\
n=37\end{array}$ & $\begin{array}{l}\text { All Subjects } \\
\quad n=93\end{array}$ \\
\hline & $\mathrm{S}_{\mathrm{pCO}} \geq 6 \%$ & $\mathrm{~S}_{\mathrm{pCO}} \geq 9 \%$ & $\mathrm{~S}_{\mathrm{pCO}} \geq 9 \%$ \\
\hline Sensitivity & $81.0(58.1-94.6)$ & $100(47.8-100)$ & $73.1(52.2-88.4)$ \\
\hline Specificity & $74.3(56.7-87.5)$ & $96.9(83.8-99.9)$ & $89.6(79.7-95.7)$ \\
\hline Positive predictive value & $65.4(44.3-82.8)$ & $83.3(35.9-99.6)$ & $73.1(52.2-88.4)$ \\
\hline Negative predictive value & $86.7(69.3-96.2)$ & $100(88.8-100.0)$ & $89.6(79.7-95.7)$ \\
\hline \multicolumn{4}{|c|}{$\begin{array}{l}\text { Values are percentage and } 95 \% \text { CIs. } \\
* \text { The reference standard carboxyhemoglobin }(\mathrm{COHb}) \text { levels for the diagnosis of carbon monoxide }(\mathrm{CO}) \text { poisoning were: } \mathrm{COHb}>5 \% \text { in non-smokers, and } \mathrm{COHb}>10 \% \text { in smokers and entire } \\
\text { cohort. } \\
\mathrm{S}_{\mathrm{pCO}}=\text { carboxyhemoglobin measured via pulse CO-oximetry }\end{array}$} \\
\hline
\end{tabular}

\section{Limitations}

The study was conducted in a single center. The results may not be directly extrapolated to other patient populations and clinical settings, including in-hospital conditions. The $\mathrm{COHb}$ measurements were performed upon admission to the ED, following $\mathrm{CO}$ exposure. There was a 19-min median time interval between blood sampling and $\mathrm{S}_{\mathrm{pCO}}$ measurement. This time interval remained below the $\mathrm{COHb}$ halflife, even for patients treated with normobaric $100 \%$ oxygen, with a limited systematic bias regarding timing of either measurement. The time-lapse from the end of $\mathrm{CO}$ exposure, as well as the possible oxygen therapy provided by pre-hospital emergency services, prior to ED management, may explain the relatively low $\mathrm{COHb}$ values in our entire subject cohort. Nevertheless, this reflects real ED conditions, with patients presenting to the ED with various time lapses after $\mathrm{CO}$ exposure. Based on the thresholds of $>10 \%$ in smokers and $>5 \%$ in non-smokers, $28 \%$ of our cohort were diagnosed with CO poisoning. Few subjects presented with high $(>15 \%)$ or very high $(>25 \%) \mathrm{COHb}$.

The time between the end of $\mathrm{CO}$ exposure and ED admission, and the use and duration of oxygen therapy were not recorded. Methemoglobinemia, which could also be a source of error in the detection of $\mathrm{COHb}$ levels, was not assessed.

\section{Conclusions}

$\mathrm{S}_{\mathrm{pCO}}$ measurements from the RAD-57 cannot be used as a substitute for standard blood $\mathrm{COHb}$ measurement in ED patients with suspected $\mathrm{CO}$ poisoning. However, pulse CO-oximetry could be useful as a first-line screening test, enabling rapid detection and management of $\mathrm{CO}$-poisoned patients in the ED.

\section{ACKNOWLEDGMENTS}

We thank Dr Vahid Hosseini for contributing to the study. We thank the emergency department nurses, physicians, and other staff for their kind support of the study, and Josh Rubenovitch MD, Julie Carr MD, and Jonathan Clarke MD for contributing to English translation.

\section{REFERENCES}

1. Raub JA, Mathieu-Nolf M, Hampson NB, Thom SR. Carbon monoxide poisoning: a public health perspective. Toxicology 2000;145(1):1-14.

2. Iqbal S, Law HZ, Clower JH, Yip FY, Elixhauser A. Hospital burden of unintentional carbon monoxide poisoning in the United States, 2007. Am J Emerg Med 2012;30(5):657-664.

3. Gajdos P, Conso F, Korach JM, Chevret S, Raphael JC, Pasteyer J, et al. Incidence and causes of carbon monoxide intoxication: results of an epidemiologic survey in a French department. Arch Environ Health 1991;46(6):373-376.

4. Ernst A, Zibrak JD. Carbon monoxide poisoning. N Engl J Med 1998;339(22):1603-1608.

5. Hampson NB, Scott KL, Zmaeff JL. Carboxyhemoglobin measurement by hospitals: implications for the diagnosis of carbon monoxide poisoning. J Emerg Med 2006;31(1):13-16.

6. Hampson NB, Hauff NM. Carboxyhemoglobin levels in carbon monoxide poisoning: do they correlate with the clinical picture? Am J Emerg Med 2008;26(6):665-669.

7. Hampson NB, Piantadosi CA, Thom SR, Weaver LK. Practice recommendations in the diagnosis, management, and prevention of carbon monoxide poisoning. Am J Respir Crit Care Med 2012;186(11): 1095-1101.

8. Weaver LK. Clinical practice. Carbon monoxide poisoning. N Engl J Med 2009;360(12):1217-1225.

9. Maisel WH, Lewis RJ. Noninvasive measurement of carboxyhemoglobin: how accurate is accurate enough? Ann Emerg Med 2010; 56(4):389-391.

10. Coulange M, Barthelemy A, Hug F, Thierry AL, De Haro L. Reliability of new pulse CO-oximeter in victims of carbon monoxide poisoning. Undersea Hyperb Med 2008;35(2):107-111.

11. Suner S, Partridge R, Sucov A, Valente J, Chee K, Hughes A, Jay G. Non-invasive pulse CO-oximetry screening in the emergency department identifies occult carbon monoxide toxicity. J Emerg Med 2008; 34(4):441-450.

12. Piatkowski A, Ulrich D, Grieb G, Pallua N. A new tool for the early diagnosis of carbon monoxide intoxication. Inhal Toxicol 2009; 21(13):1144-1147.

13. Kot J, Sićko Z, Góralczyk P. [Carbon monoxide pulse oximetry vs direct spectrophotometry for early detection of CO poisoning]. Anestezjol Intens Ter 2008;40(2):75-78. Article in Polish.

14. Touger M, Birnbaum A, Wang J, Chou K, Pearson D, Bijur P. Performance of the RAD-57 pulse CO-oximeter compared with standard laboratory carboxyhemoglobin measurement. Ann Emerg Med 2010;56(4):382-388.

15. Roth D, Herkner H, Schreiber W, Hubmann N, Gamper G, Laggner AN, Havel C. Accuracy of noninvasive multiwave pulse oximetry 


\section{Emergency Department Management of Suspected Carbon Monoxide Poisoning}

compared with carboxyhemoglobin from blood gas analysis in unselected emergency department patients. Ann Emerg Med 2011; 58(1):74-79.

16. Weaver LK, Churchill SK, Deru K, Cooney D. False positive rate of carbon monoxide saturation by pulse oximetry of emergency department patients. Respir Care 2013;58(2):232-240.

17. Barker SJ, Curry J, Redford D, Morgan S. Measurement of carboxyhemoglobin and methemoglobin by pulse oximetry: a human volunteer study. Anesthesiology 2006;105(5):892-897.
18. Zaouter C, Zavorsky GS. The measurement of carboxyhemoglobin and methemoglobin using a non-invasive pulse CO-oximeter. Respir Physiol Neurobiol 2012;182(2-3):88-92.

19. Bland JM, Altman DG. Statistical methods for assessing agreement between two methods of clinical measurement. Lancet 1986;1(8476): 307-310.

20. Hampson NB. Noninvasive pulse CO-oximetry expedites evaluation and management of patients with carbon monoxide poisoning. Am J Emerg Med 2012;30(9):2021-2024.

This article is approved for Continuing Respiratory Care Education credit. For information and to obtain your CRCE

(free to AARC members) visit

www.rcjournal.com 